\title{
The Paradox of Democracy in the Western Modern Design Movement—Thinking about the Megastructure
}

\author{
Xin Sun, Yun Tong ${ }^{* 1}$ \\ School of Fine Arts Nanjing Normal University, Nanjing 210043, China
}

\begin{abstract}
As the beginning of a new type culture, the movement of modernism signify break with traditional culture, it reshaped the aspects of people's lives with innovators attitude. In this process, the modern design masters as a preacher with the pious attitude, they actively establish the value system of their own, and set a footnote in the earth to the design scheme of the huge amount of practice. In order to find suitable aesthetic form for new materials and new technology, they throw themselves into the logical relation between technology and function. However, at the very nature level, such design system under the guidance of materiality, apparently ignored the diverse needs of people in biological and psychological factors, so that the starting point of democracy increasingly untenable. Especially in the mega structure landscape later, the designer has evolved into an arbitrary image of the creator, and toward the opposite of democracy under the guidance of capital.
\end{abstract}

Keywords: Modern Design; Democracy; Utopia; Megastructure

Numerous social issues triggered by industrialization in western countries from $18^{\text {th }}$ to $19^{\text {th }}$ century have become increasingly prominent when the role of professional designer emerged in the late $19^{\text {th }}$ and early $20^{\text {th }}$ century. At that time, socially responsible artists, sociologists and urbanologists with different backgrounds started throwing themselves to design related practices. Many renowned figures tried to popularize their aesthetics theories and solve social issues by designing, education and exhibition, such as Ebenezer Howard, the founder of the English garden-city, William Morris, the leader of the Arts and Crafts Movement and John Ruskin. They regard solving social problems as their compelling obligations. However, modernism deviated from democratism inherited at the early stage when politics and market economy started to play their roles in the huge capital operation system. The paper will focus on modality of megastructure, throughout modern movements, at different stages as well as how it evolves into another capitalist tool for ruling.

\section{Functionalism and Democratism at Early Modernism}

Modernism's enduring advantage in ideology has been sustained by morality and political connotation. It assumes that many extreme dissenters are closely tied with enforceable regime, such as German of national socialism and Russia of Stalin era. Modernists deem themselves as enabler for the common public to realize aesthetics of "the mechanical age". They liberate themselves from shackle of historicism and study innovative forms and materials, which are symbolical, if not realistic, in consistent with advanced industrial culture's mass productivity ${ }^{[1]}$.

\section{-Twentieth-Century Design}

As stated, mechanical aesthetics mirroring the spirt of the times serves as acting force of modern movements in moral aspect at early stage. The megastructure first appeared at large-scale public projects and facilities, such as bridge pier, granary and factories. Their modeling, without any sign of decoration, is an external manifestation for intrinsic functionality and structure. The granary shown in Figure 1 serves as a significant representative for early American industrial architecture. It reflects ultimate pursuit for maximum energy efficiency. The storage and lifting system have witnessed continuous evolution on structure and material before the below steel can and tank takes shape. There are four major contributing factors hereunder. 1. production requiring relative material and special technology; 2. dealing with rusting and corrosion; 3. thermal insulation of steel; 4. consideration on geometric problems. The design philosophy starting with consideration on absolute physicality has made Banham to deem it as source for European modernism at one time.

1 About the author: Xin Sun, male, 1979, PHD, School of Fine Arts Nanjing Normal University, Associate professor, Research on Artistic Design.

Corresponding Author: Yun Tong, Female, 1981, Nanjing, PHD, School of Fine Arts Nanjing Normal University, lecturer, Research on Artistic Design.

Copyright (C) 2020 Xin Sun et al.

doi: $10.18282 / 1-e . v 9 i 2.1391$

This is an open-access article distributed under the terms of the Creative Commons Attribution Non-Commercial License

(http://creativecommons.org/licenses/by-nc/4.0/), which permits unrestricted non-commercial use, distribution, and reproduction in any medium, provided the original work is properly cited. 
Politically, complete abandoning on traditional rigid hierarchy represents penetration of democracy to some degree. On one hand, the democracy is embodied in rational design for labor's residential and working environment; on the other hand, it is reflected in designer's free attitude towards material and construction. The Crystal palace shown in Figure 2 is for the Great Exhibition in 1851 designed by Paxton. He innovatively applied cheap glass as main construction material and completed the project in an efficient way by splicing. Obviously, this manner has broken the tradition and mental shackles that buildings must be deeply rooted under the ground. It focuses more on finding solutions based on practical problems. There is universally equal mentality contained, which believes that fruits of industrial revolution shall be shared by all mankind. In this connection, we can find that design practices in early stage of modern movements mostly appeal to reality and democracy. The original intentions of designer and final results are pure as a consequence. To some extent, the above mentioned "democracy" and "politics" set the tone for modernism.

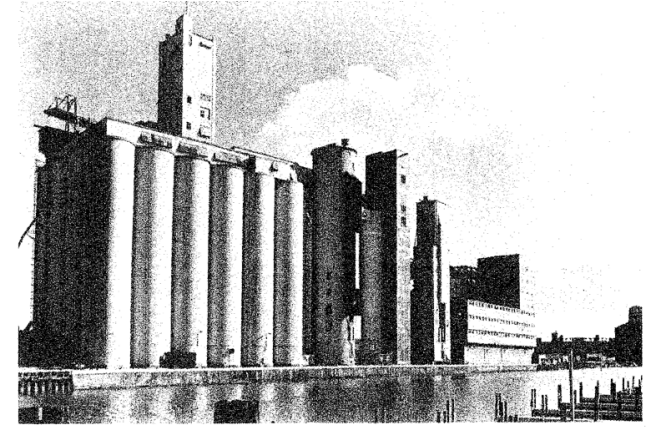

Figure 1. Common granary in western American in early $20^{\text {th }}$

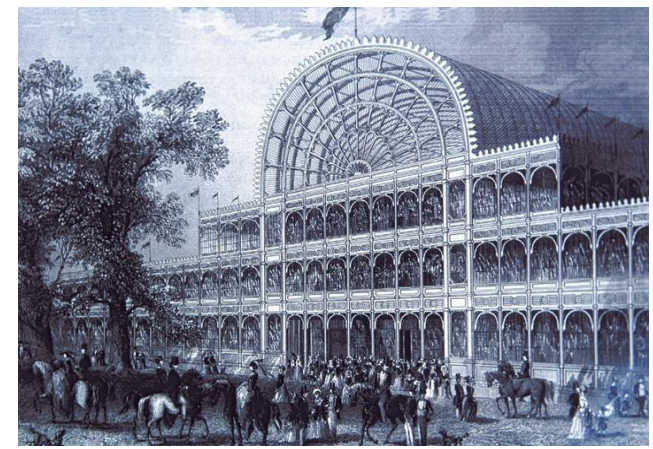

Figure 2. Crystal Palace established in 1851.

\section{Flourishing Modernisms}

Up until now, human come to realize the truth that machine serves as the real personality liberator. So we can see that the era of machine is the real era of democracy, of which, human life is built on beautiful and fertile land: the growth of life is full of joy beyond lines on surface of earth------It stands for lines of freedom for mankind. Human horizon can be unlimitedly broadened by machines, as a creature of human brain, which serves human mind ${ }^{[3]}$.

Wright

The above-mentioned pioneering designer's optimism always derives from self-complacence. "Artists discover beauty from instantaneity while city dwellers invent sophistication, indifference and schemes to cope with the instantaneity and uncertainty." ${ }^{[4]}$ by Minan Wang in Modernity. As forerunners, modernists smell diverse possibilities but labors at lower class suffer from drastic changes. Therefore, modernists fail to solve real issues although they devote themselves to social reforms.

Especially during the process when modern design movements keep evolving, rationalism, constructivism, futurism and hightech all explore respective "Mechanical Aesthetics" and establish relatively well-developed mindset to set up a flag. At this time, urban architecture designs focus not merely on simple residential problems and meet purely functional needs, but try to deal with operation related problems comprehensively and systematically. These individual designers or the designing population, different from politicians of utopian socialism, are aimed to build a utopian world through practical architecture and urban programs.

The high-rise glass and steel framed structure as well as the "less is more" approach by Ludwig Mies van der Rohe can be selected as the most prominent representative for the sober and rational modernism. The "less is more" in design maximumly reflect his architecture and artistic characteristics and even inspire and enlighten the world afterwards. The pure and meaningless structures seemingly convey his abandonment on personal desires but has become standard for popular architecture. During his whole life for creation and as the father for steel and glass structure, he remains committed to being guided by his philosophies rather than being driven by users' domestic and external demand or environments in architecture. In this sense, his theory serves as horn for dictatorship, instructing users to work as machines. Seagram Building as shown in Figure $\mathbf{3}$ is one of his masterpieces. The square like glass box restricts people's life in the pre-determined scene. The giant delivers certain sense of authority and oppression. Future urban cities and building landscapes sustained by technologies are more utopian in the view of the radical futurists.

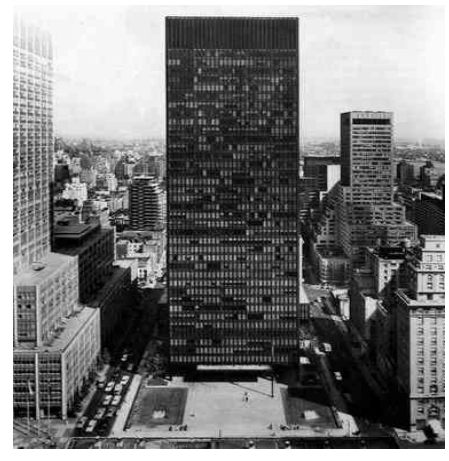

Figure 3. Seagram Building by Mies van der Rohe

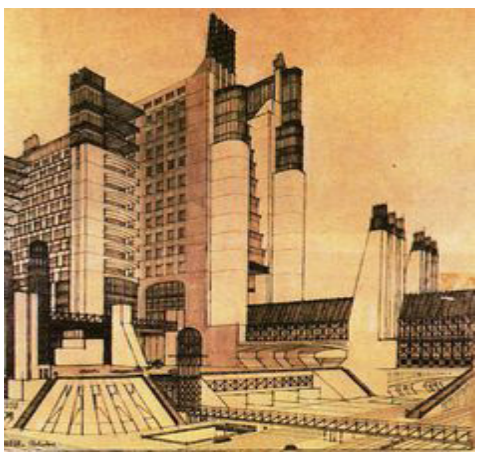

Figure 4. Sant Elia of futurism in 1948 


\section{Megastructures and High-tech Architecture of Late Modernism}

The whole industrial engineering must be combined and develop together with clubs, hotels, stores, apartment and even theaters. This kind of arrangement will finally enable strong economy and will reduce human's mental suffering. Workers don't need to step on sidewalks after being put into a unified system ${ }^{[5]}$ — "City under a single roof" by Raymond Hood

Skyscrapers keep multiplying in urban cities especially in late modernism. Even before 1964, the recognized "Mega Year" in design community, Manhattan of 1930s has become testing ground in this regard. However, Reyner Banham has elaborated on it in his book Megastructure: Urban Futures of the Recent Past up until 1976. The megastructure thereafter has got rid of mysterious utopia and become widespread in the world. And high-tech architecture derive and emerge thereafter.

Rapid development is accompanied by opportunities and threats. On one hand, megastructure gives prominence to integrity and mobility of design. It enables efficient production and social functioning to integrate resources in a more ingenious way. Centre Pompidou as shown in Figure 5 stood as the most typical representative at that time. "The bright colors, ingenious style, inflatable products, adjustable accessories, huge projection screen empower it become an outstanding and attractive architecture at the

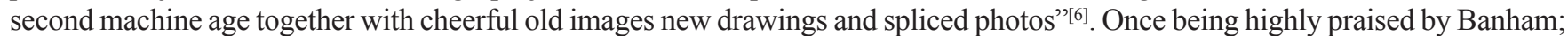
On the other hand, the design completely from top to down, oppression by huge volume and absolute control by homogenized design have revealed authority of capitalism to some extent. The HSBC building as in Fig. 6 accomplished by Foster \& Partners aims to sweep up congestion on the ground and boring blocks and streets but build intricate and diversified space vertically.

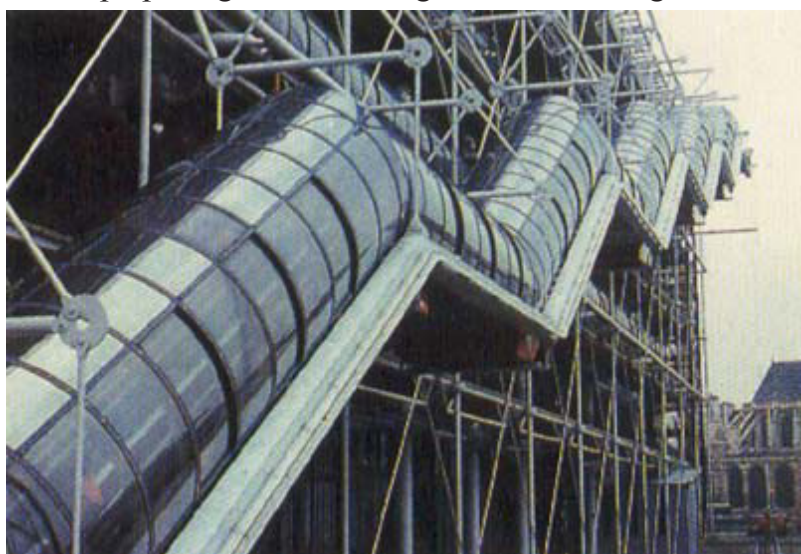

Figure 5. Centre pompidou by renzo piano.

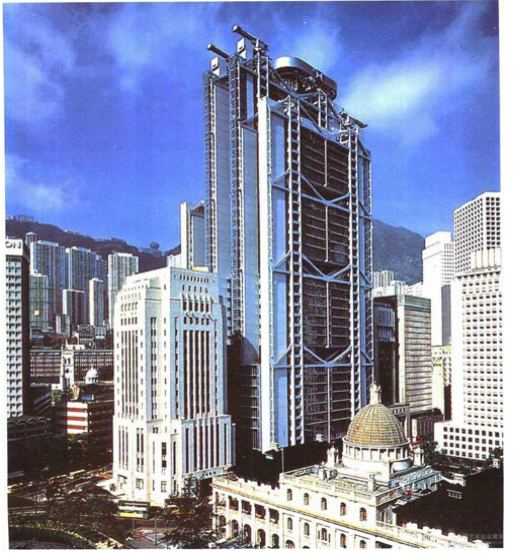

Figure 6. HSBC building by Foster \& Partners.

\section{Possibilities in contradiction resolution of economy between pioneers and capitalists}

Contradictions between pioneers and capitalists have been intensified even more later because of deviation in values. Pioneers devote themselves to future development-oriented solutions while shrewd merchants tend to make use of it as a ruling approach for economy and politics. Unfortunately, power of disclosure is always under control of the capitalists. Arata Isozaki, therefore, explored the solutions failed for all kinds of reasons in his book Unbuilt and rediscovered and interpreted theories and practical significance boasted by those experimental cases.

While those megastructure landscapes led by large economic and political groups have gradually evolved into comprehensive and efficient machines of monopoly and authority. In these circumstances, people's majority paths have been preset by designers, which has turned into autocracy in nature.

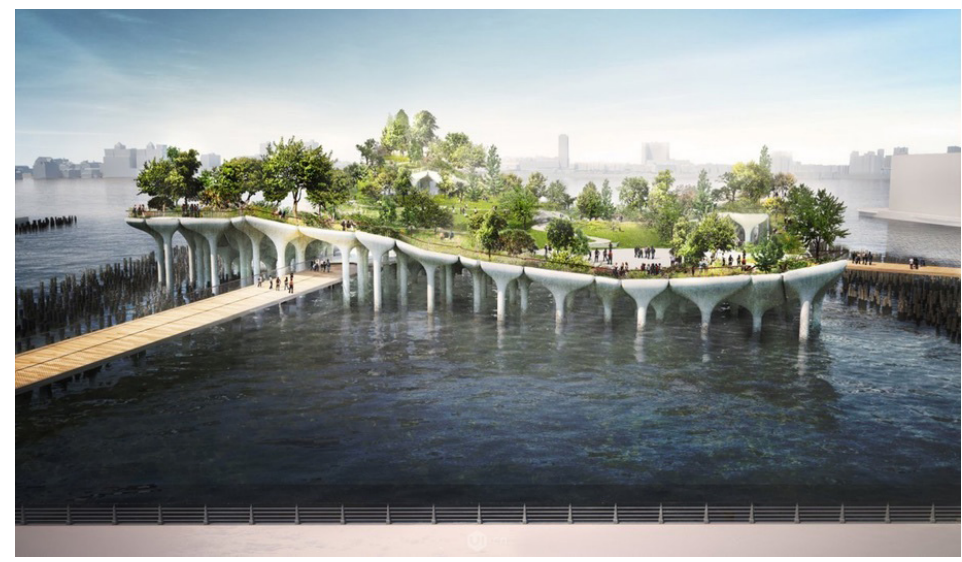

Figure 7. Image and Sound Museum in Rio de Janeiro.

It can be concluded that modernism design mode of top-down has reached an ultimate level. It has been questioned by more and more people because experience-based economy has become mainstream today. To explore new opportunities, pioneers of imagination and responsibility are striving for more space for users to give full play to subjective creativity. Figure 7 is the Image and Sound Museum in Rio de Janeiro designed Roberto Burle Marx, who works as a landscape designer, painter, ecologist and naturalist. The giant integrating with nature enables diverse audio-visual experience. Therefore, the focus on machine aesthetics 
has been transformed to shaping scenes for uncertainty-based experience. That is the major transformation in terms of design field. In summary, it is an inevitable way to consider both rationally and emotionally to solve the problems with regard to "person" as the core object.

\section{References}

1. Jonathan M. Woodham (2012). Twentieth-Century Design, Translated by Bo Zhou, Ying Shen. Shanghai: Shanghai People's Publishing House, pp.43.

2. Reyner Banham. A concrete Atlantis: U.S(1986). Industrial Building and European Modern Architecture, 1900-1925. Cambridge, Mass.: MIT Press.

3. Frank Lloyd Wright (2010). Wright on American Architecture, Translated by Yong Jiang, Zhentao Li. Beijing: China Industry Press, pp.242.

4. Minan Wang (2012). Modernity. Nanjing: Nanjing University Press, pp.22.

5. Rem Koolhaas, Delirious New York (2015): A Retroactive Manifesto for Manhattan, Translated by Keyang Tang. Beijing: Sanlian Book Store, pp.269.

6. Reyer Banham (1976). Megastructure: Urban Futures of the Recent Past. New York: Harper\& Row, pp.84.

7. Arata Isozaki (2001). Unbuilt. Beijing: China Building Industry Press. 